\title{
Prispevek k verodostojnosti podatkov o ustanovitvi čitalnic na Slovenskem
}

\section{Contribution to the Credibility of Data Concerning the Foundation of Reading Societies in Slovenia}

Ključne besede: slovenska glasba, 19. stoletje, čitalnice, zgodovina glasbe

\section{IZVLEČEK}

Mnenja o datumih ustanovitve čitalnic na Slovenskem so deljena. Zlasti velja to za mariborsko in ljubljansko čitalnico. Medtem ko nekateri muzikologi trdijo, da je za Narodno slovansko čitalnico v Trstu (29. januarja 1861) bila kot druga ustanovljena ljubljanska Narodna čitalnica (20. oktobra 1861) in nato kot tretja mariborska Narodna slovanska čitalnica (4. septembra oziroma 10. novembra 1861), meni večina raziskovalcev tega obdobja, da je treba upoštevati formalni datum ustanovitve, ko so ustanovitelji s podpisi potrdili ustanovitveni zapisnik, kar je bilo v Mariboru 17. julija 1861.
Keywords: Slovenian music, reading societies, 19th century, history of music

\section{ABSTRACT}

The musicological debate can not agree about the date of the births of the reading societies in Slovenia. This holds true especially for the foundation of reading societies in Maribor and Ljubljana. Some musicologist are convinced that the birth of National Slavonic Reading Society in Triest (on $29^{\text {th }}$ January 1861) was followed consecutively by foundation of National Reading Society in Ljubljana (on $20^{\text {th }}$ October 1861) and National Slavonic Reading Society in Maribor (on $4^{\text {th }}$ September or on $10^{\text {th }}$ November). However the majority of scholars points out that as the formal foundation date should be considered the day on which the founders confirmed with their signatures the first protocol what happened in Maribor already on $17^{\text {th }}$ July 1861. 
Pri prebiranju muzikološkega tiska zadnjih nekaj let sem zasledila razhajanja v navajanju podatkov glede ustanovitve čitalnic na Slovenskem pa tudi dvojna merila v ugotavljanju datuma ustanovitve prvih treh - tržaške, mariborske in ljubljanske. Ivan Klemenčič v svojem članku Glasbeni prispevek slovenskemu narodnemu prebujanju. Vloga čitalnic med Trstom, Ljubljano in Mariborom (1848-1872) - objavljenem v spominskem zborniku, posvečenem Danilu Pokornu, piše med drugim: "Tako ni brez simbolike dejstvo, da je bila 1861 najprej ustanovljena Slovanska čitalnica v Trstu (29. januarja), za njo Narodna čitalnica v Ljubljani (20. oktobra) in nato Slovanska čitalnica Maribor (10. novembra) «. ${ }^{1}$ Klemenčič se je očitno oprl na podatek, ki ga je davnega leta 1960 zapisal v svoji Zgodovini glasbene umetnosti na Slovenskem Dragotin Cvetko: „Prva čitalnica se je osnovala v Trstu. Njeni utemeljitelji so se v ta namen prvič zbrali 29. januarja 1861, odbor pa se je konstituiral na ustanovnem občnem zboru 24. marca istega leta. Društvo se je imenovalo Slovanska, tudi Narodna slovanska čitavnica; oblasti so mu potrdile pravila v začetku septembra 1861 [...]. Ljubljanska narodna čitavnica je imela ustanovni občni zbor 20. oktobra, mariborska Slovanska čitavnica pa 10. novembra 1861 “. ${ }^{2}$ Nataša Cigoj Krstulović navaja v svoji magistrski nalogi Glasbeno delo čitalnic na Slovenskem, do ustanovitve Glasbene matice 1848-1872 spet nekoliko "drugačne" podatke: "Ljubljanska Narodna čitalnica, ki se je ustanovila kot druga za tržaško, je v prvem desetletju zadržala privilegij središča slovenskega kulturnega in političnega življenja v habsburški provinci«. V 110. opombi pa zapiše: "Cesarsko kraljevo predsedstvo v Ljubljani je ljubljanski Narodni čitalnici odobrilo pravila 30. avgusta 1861. Nekaj dni zatem (4. septembra) pa je cesarsko kraljevo namestništvo v Gradcu dovolilo mariborsko Narodno čitalnico, zato se je le-ta ustanovila kot tretja in ne kot druga, kot je večkrat navedenow. Ne navede pa natančnega vira in ne avtorjev. ${ }^{3}$

Ko sem zbirala gradivo za diplomsko nalogo o mariborski čitalnici (mentor je bil D. Cvetko) in sem nalogo pozneje v predelani in skrajšani obliki objavila v reviji Nova obzorja 1962 z naslovom Slovensko glasbeno življenje v Mariboru v dobi čitalnice ${ }^{4}$, sem se obrnila za nasvet na najvidnejšega raziskovalca zgodovine mariborske Narodne čitalnice, pesnika in bibliotekarja Janka Glazerja. Posebej me je opozoril na svoja dva članka, natisnjena v Mariborskem večerniku Jutra leta 1931 in 1932. V prvem, O ustanovitvi Čitalnice v Mariboru ob 70-letnici ustanovitve (18. julija) 5 navaja natančne podatke o poteku dogodkov ob ustanovitvi mariborske čitalnice. Omenja tudi dokumente, ki jih je "v zvezi s prijavo čitalnice politični oblasti“ našel v Deželnem arhivu v Grad$\mathrm{cu}$, pri čemer je poleg pravil čitalnice (v izvirniku v nemškem jeziku) zanimiv zlasti nemški prevod zapisnika o ustanovitvi mariborske čitalnice 17. julija 1861, ki ga je podpisalo dvajset rodoljubov, prvih članov čitalnice; priloženo pa je tudi pozdravno pismo škofa Antona Martina Slomška, napisano 18. julija 1861.

Drugi Glazerjev članek Prvi slovenski koncert v Mariboru in njegove posledice. K proslavi sedemdesetletnice ${ }^{6}$ pa opisuje predvsem dogodek - slavnost ob prvi obletnici mariborske čitalnice 3. avgusta 1862. Proslavo ob prvi obletnici mariborske čitalnice 3. avgusta 1862 pa pred Glazerjem omenja že Hinko Druzovič v razpravi Zgodovina slovenskega petja v Mariboru. ${ }^{7}$

\footnotetext{
Ivan Klemenčič, "Glasbeni prispevek slovenskemu narodnemu prebujenju. Vloga čitalnic med Trstom, Ljubljano in Mariborom (1848-1872)“, Muzikološke razprave. In memoriam Danilo Pokorn, ur. Nataša Cigoj Krstulović, Tomaž Faganel, Metoda Kokole. Ljubljana: Založba ZRC SAZU, $2004,105$.

Dragotin Cvetko, Zgodovina glasbene umetnosti na Slovenskem III. Ljubljana, Državna založba Slovenije $1960,138$.

3 Nataša Cigoj Krstulović, Glasbeno delo čitalnic na Slovenskem do ustanovitve Glasbene matice (1848-1872), magistrska naloga. Ljubljana 1997, 42 .

Manica Špendal, Slovensko glasbeno življenje v Mariboru v dobi čitalnice, Nova obzorja 15 (1962) 5-6, 246-256.

Janko Glazer, O ustanovitvi Čitalnice v Mariboru, Mariborski večernik Jutra 5 (1931) 160, 18. 7., 2. Manica Špendal, Prispevek Janka Glazerja k zgodovini mariborske čitalnice, Glazerjev zbornik, Časopis za zgodovino in narodopisje 67 (1977) $13,72-75$.

Janko Glazer, Prvi slovenski koncert v Mariboru in njegove posledice. K proslavi sedemdesetletnice, Mariborski večernik Jutra 6 (1932) 249 , 2. $11 ., 3$.

Hinko Druzovič, Zgodovina slovenskega petja v Mariboru, Časopis za zgodovino in narodopisje 19 (1924) 2,96 -100.
} 
Dogajanje v času čitalnic - osrednjih slovenskih kulturnih organizacij, so - poleg muzikologov in glasbenih pedagogov - raziskovali tudi drugi slovenski kulturni zgodovinarji. Poleg J. Glazerja literarni zgodovinar Ivan Prijatelj. V četrtem delu Slovenske kulturne in politične zgodovine (1848-1895), iz leta 1938, meni med drugim: "Prva čitalnica, ki se je v tej dobi ustanovila na slovenskih tleh, je bila torej tržaška, njen rojstni dan je 29. januar 1861 [...]. Medtem je Ljubljano z ustanovitvijo čitalnice prehitel še Maribor. Že v prihodnji številki je namreč 'Novicam' poročal dopisnik iz tega mesta: 'Česar smo pri nas davno že živo potrebovali, se je ustanovilo: društvo, kjer se slovensko govori in bere [...]. Tedaj je dne 14. julija dr. Sernec sklical v stanovanje dr. Dominkuša družbo rodoljubov, 17. julija so se izdelala pravila, in sedaj, glej ptujec, če te naša reč zanima, pri g. Šramelju ${ }^{8}$ stopaj brez nekoliko stopnic v prav mičen vhod in zagledaš zlasti napis: 'Slovanska čitavnica'«?

Poleg tega moremo v Novicah, 16. septembra, ("Iz Tersta ") prebrati tudi: "Z veseljem smo slišali, da tudi v Ljubljani snujete veliko čitavnico, kakršne je po pravici pričakovati v pervem slovenskem mestu “. ${ }^{10}$ Že 1. septembra pa so Novice zabeležile, da je mariborske Slovence počastil s svojim prihodom "ščit in ljubljenec slovenskega naroda, gospod državni poslanec dr. Lovro Toman. Obiskal je našo mlado 'čitavnico' in z navdušljivimi besedami okrepil pričujoče članove [...] „11

Zelo izčrpno je obdelal v svojih razpravah in monografijah kulturno zgodovino Maribora in mariborske Slovanske čitalnice Bruno Hartman. V razpravi Slovanska čitalnica v Mariboru in njeni knjižnici je uvodoma zapisal: "Slovanska čitalnica v Mariboru' (takšno je bilo njeno uradno ime, sicer pa so jo imenovali - tudi njen odbor - Narodna slovanska čitalnica, Slovenska čitalnica, Narodna čitalnica ali kar Čitalnica v Mariboru) je obstajala od 17. julija 1861, ko so njeni ustanovitelji s podpisi potrdili ustanovitveni zapisnik (štajersko državno namestništvo je njena pravila potrdilo 4. septembra 1861), pa do aprila 1941, ko jo je odpravil ukrep okupacijske oblasti. Ustanovili so jo bili mariborski slovenski naravnani meščani pod vodstvom odvetniških pripravnikov dr. Janka Serneca in dr. Janka Ploja . ${ }^{12}$

V monografiji Zgodovina slovenskega dramskega gledališča v Mariboru do druge svetovne vojne pa Hartman meni glede datumov nastanka čitalnic takole: "Ljubljančane so prehiteli Tržačani, ki so čitalnico ustanovili 29. januarja 1861, nato pa so bili urnejši od Ljubljančanov še v Mariboru, kjer so jo s pravili izoblikovali 17. julija 1861 [...] «. ${ }^{13}$ Tudi v svoji zadnji monografiji Kultura v Mariboru ugotavlja Hartman podobno: "Osrednja slovenska kulturna organizacija v Mariboru je bila Slovanska čitalnica, ki so jo ustanovili leta 1861, takoj za tržaško. “14

V Enciklopediji Slovenije v članku Čitalništvo pa moremo prebrati: „Prva čitalnica v tej dobi je bila Slovanska čitalnica v Trstu, ustanovljena 29. 1. 1861, sledila ji je mariborska Narodna čitalnica in 30. 8. 1861 ljubljanska [...] $]^{15}$

V Kroniki slovenske zgodovine Slovenci skozi čas iz leta 1999 je o nastanku čitalnic na Slovenskem zapisano: „17. 7. 1861 so v Mariboru slovenski rodoljubi ustanovili Slovansko čitalnico. Mariborska čitalnica je bila druga na Slovenskem. Prva širšeslovenska je bila ustanovljena že januarja 1861 v Trstu, tretja je bila ustanovljena oktobra 1861 v Ljubljani.« 16

Že samo na tem mestu zbrani citati nekaterih najvidnejših raziskovalcev obdobja treh prvih čitalnic na Slovenskem, jasno kažejo, da menijo vsi, da je avtentičen datum ustanovitve mariborske

\footnotetext{
Nemški gostilničar Carl Schramel je bil lastnik pivnice Pri moki (Mehlgrube) v severnozahodnem kotu Rotovškega trga (danes je na tem mestu Mariborska knjižnica), v kateri je najela svoje prve prostore mariborska čitalnica.

9 Davorin Trstenjak iz Maribora, Narodna čitavnica v Mariboru, Novice 19 (1861) 34, 21. 8., 277-278. Nav. po Ivan Prijatelj, Kulturna in politična zgodovina Slovencev 1848-1895, Ljubljana 1938, 12-14.

10 Novice 19 (1861) 38, 18. 9., 323.

11 Novice 19 (1861) 36, 4. 9., 269.

2 Bruno Hartman, Slovanska čitalnica v Mariboru in njeni knjižnici, Časopis za zgodovino in narodopisje 15 (1979) 1-2, 295-296.

3 Bruno Hartman, Zgodovina slovenskega dramskega gledališča v Mariboru do druge svetovne vojne, Maribor, Obzorja, $1996,18$.

4 Bruno Hartman, Kultura v Mariboru, Maribor, Obzorja, 2001, 27.

Enciklopedija Slovenije, 2. zv., Ljubljana 1988, 137.

Kronika slovenske zgodovine. Slovenci skozi čas, Ljubljana, Založba Mihelač, 1999, 164.
} 
Narodne slovanske čitalnice 17. julij 1861, torej dan, ko so njeni ustanovitelji (20 rodoljubov) s podpisi potrdili ustanovitveni zapisnik društva. Pomembno je tudi, da so v Mariborski čitalnici takoj po ustanovitvi organizirali čitalniški zbor, ki je nastopil že 23. avgusta 1861 - (ob obisku dr. Lovra Tomana v Mariboru). Omenim naj še enkrat navedbo D. Cvetka v Zgodovini glasbene umetnosti na Slovenskem, da so oblasti potrdile pravila Narodne slovanske čitalnice v Trstu v začetku septembra $1861 .{ }^{17}$ Če bi veljal kot datum ustanovitve čitalnic dan, ko so jih oblasti "dovolile“, bi tržaška čitalnica potemtakem ne bila prva, ampak bi veljala za prvo ustanovljeno ljubljanska Narodna čitalnica. Vsekakor bodo v prihodnosti morali vsi, ki bodo raziskovali obdobje čitalnic na Slovenskem, upoštevati mnenja navedenih piscev in ne kar pavšalno postavljati datumov ustanovitve posameznih čitalnic.

\section{SUMMARY}

The musicological debate can not agree about the date of the births of the reading societies in Slovenia (in Triest, Maribor and Ljubljana). This holds true especially for the foundation of reading societies in Maribor and Ljubljana. Some musicologist are convinced that the birth of National Slavonic Reading Society in Triest (on $29^{\text {th }}$ January 1861) was followed consecutively by foundation of National Reading Society in Ljubljana (on $20^{\text {th }}$ October 1861) and National Slavonic Reading Society in Maribor (on $4^{\text {th }}$ September or on $10^{\text {th }}$ November). However the majority of scholars from other scientific professions (historians, literary historians, library scholars a.o.) points out that as the formal foundation date should be considered the day on which the founders confirmed with their signatures the first protocol what happened in Maribor already on $17^{\text {th }}$ July 1861 . This article conceived as collection of credible citations warns the future scholars of similar mistakes and wants to prevent from their repeating.

17 Dragotin Cvetko, Zgodovina glasbene umetnosti na Slovenskem III, Ljubljana, DZS, 1960, 138. 


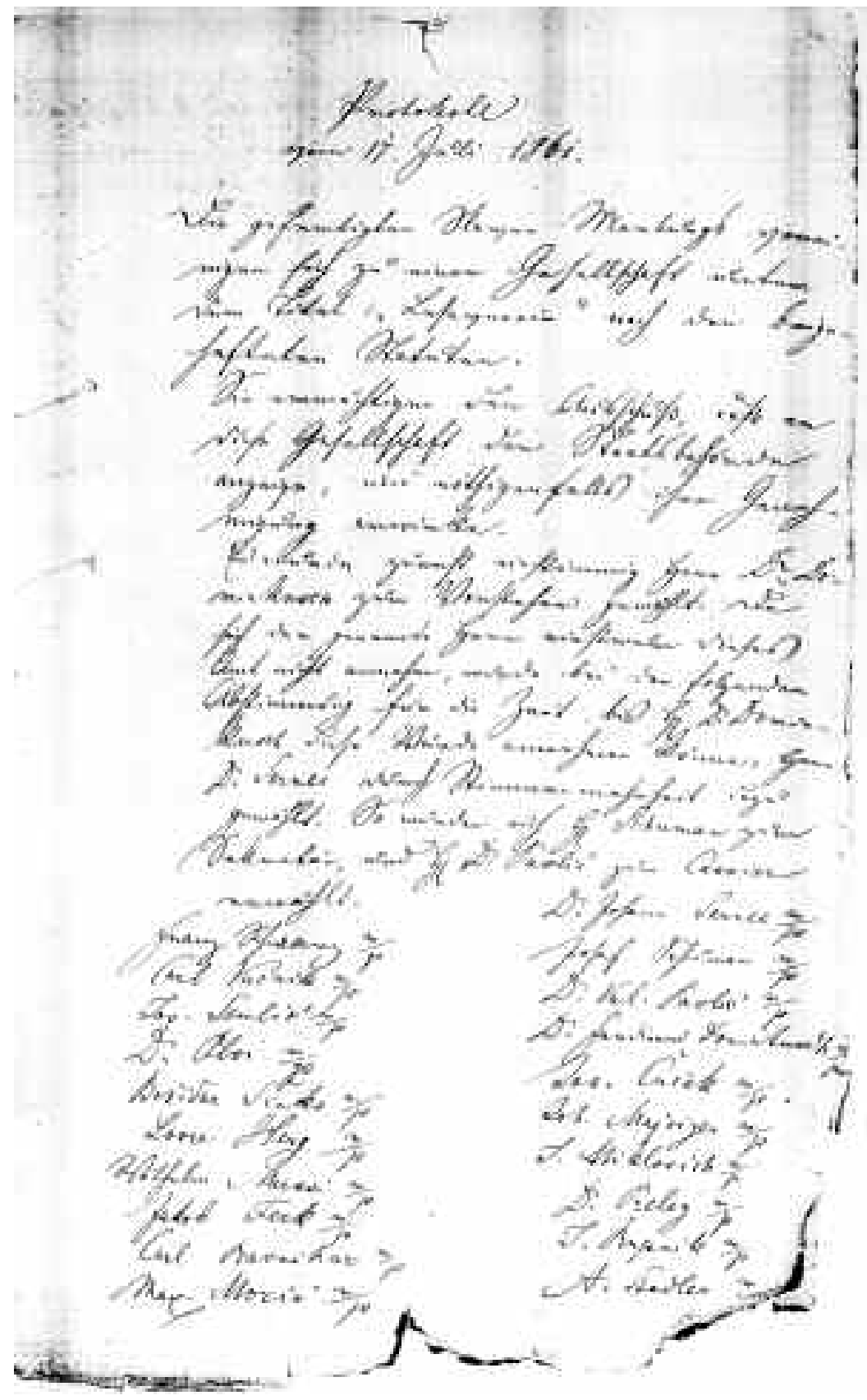

Faksimile nemškega prevoda zapisnika o ustanovitvi mariborske čitalnice 17. julija 1861, ki ga je podpisalo dvajset rodoljubov, prvih članov čitalnice. Rokopis hrani Enota za domoznanstvo Univerzitetne knjižnice Maribor, Rokopisna zbirka, Ms 201. 